\title{
Some Fundamentals of Romance Linguistics with Regard to Sardinian
}

\author{
Jordi Crespo Saumell \\ Università degli Studi di Cagliari, Cagliari, Italia \\ Email: cresaumell@gmail.com
}

Received 3 June 2015; accepted 20 June 2015; published 26 June 2015

Copyright (C) 2015 by author and OALib.

This work is licensed under the Creative Commons Attribution International License (CC BY). http://creativecommons.org/licenses/by/4.0/

(c) (i) Open Access

\begin{abstract}
When it comes to consider the vast space that Latin and the Romance languages occupy, geographical, temporal, and social dimensions pop up at least as unavoidable. In coming to grips with the evolution of the vulgar Latin into their extant reflexes, there is also unanimous agreement in regarding vowel quantity, syllable boundaries, and syllable weight as the three main concepts accounting for the progressive stages and the final aspect of the neo-Latin languages today. In reassuming such a theoretical frame, this paper is more particularly intended to give a picture of these features when applied to Sardinian. Its insular development beside the controversy on its alleged non Indo-European origin, the conservative forms the Sardinian took with regard to Latin, or the deep imprint the diverse linguistic superstrata exerted upon it are all these traits that, doubtlessly, contribute to making of the Sardinian a unique Romance standing for its own place in the scene of the minority languages.
\end{abstract}

\section{Keywords}

Romance Linguistics, Sardinian, Substratum, Latin Enculturation, Law of the Quantitative Collapse, Metaphonism, Superstratum, Catalan, Diglossia

Subject Areas: Literature, Sociology

\section{Introduction: Theoretical Frame and Methodological Remarks}

From a methodological point of view the linguistic theory seems to be able to explain the blank between the vulgar Latin and the Neo-Latin languages in a successful and convincing way, since it is possible to expound in reasoned and systematic terms the mechanisms accounting for the medial steps from the vulgar Latin to a Romance language whatsoever. The linguistic diachronic approach relies on taking the feature of the descriptiveness of the phenomena into account when lexical or phrastical material belonging to different Romance languages is put alongside. The constant variations and similarities coming upon are, moreover, liable to be put in systematic figures according to the basic demands of the nomological-deductive paradigm. To do so, to a major or minor 
degree and being more or less conscious of that, the linguists (and the romanists in particular) dwell on two general logical principles: the Principle of Transitivity [1] and what could be considered its negative counterpart; the modus tollendo tollens [2]. It is mainly by resorting to these principles that are obtained the clues (i.e. the general laws) in virtue of which when a singular constant trait is detected it is univocally pointing to a following outcome, the constant taken into consideration should stand furthermore when contrasted with another Romance language, thereby; that very lineament is seemingly to occur and to be applied to any similar case in the language subject to analysis. There is thus the factual possibility of outlining analogical descriptive figures which result productive in epistemic terms, this means that inferences of the kind if in the $X$ language we have $Y$, then in the $Z$ language it should be found $V$ are duly subject to the Popperian criteria of verification and falsability. It is thus chiefly by comparing and contrasting in light of these two principles that the Linguistics, in its historical approach, is in a position to cover the extant gap from the general (i.e. Latin) to the particular (i.e. Romance languages), what amounts to say that in setting discrete clusters of rules and procedures that operate systematically, the Linguistics has proved to be explanatory efficient, raising and gaining herewith a merited scientific status. Putting aside the general character of this introduction and further details that certainly would complicate the concern, the fact is that this is an inestimable achievement, since it looks that many fields in the Human Sciences have yet to reach such a position.

By the time to give full account of the awesome variety of contemporary Romance languages into which the vulgar Latin [3] diverged, the issue seems to be necessarily addressed from almost four different stances. In the first place, since the linguistic substratum is credited to have to do to a considerable extent with the eventual phonetic and morphological traits that will come down to a concrete language, the description of the spoken language(s) in a particular place previous to the implantation of the Latin is required. For it could be thought of this linguistic substratum as acting upon a modern Romance language in the analogous way the "fossilization" [4] is said to constraint the speakers of a language L2. Since encompassing a wide range of items, rules, and subsystems into which the speaker gets stuck, these seemingly precluding the optimal acquisition of a particular target language, the linguistic fossilization tends to be in general pejoratively regarded. But it turns out that some issues taken under consideration are clarified in virtue of the analogy substratum/fossilization hereby. By means of fossilization-like processes it is possible to explain, for example, the phonetical and the structural difficulties that millions of native speakers of Asian languages come across at pronouncing properly the sound [r]; the reason why Spanish speakers tend to make mistakes in Italian with the auxiliary verb of the verbs of movement like mettere, togliere, venire, entrare and the like [5]; the reason for Italian speakers-due to the coda restrictions of the Italian language - cannot help adding a slight vocalic epenthesis to the end of the English words broached by a consonant or, what is of more import here, why Sardinian native speakers may fail in adjoining an "a" before the accusative of person when uttering themselves in Italian [6].

In the second place, it is also valuable to make out if possible to what kind of Latin the dominated population was actually in touch, this in turn entailing two subsidiary points; the provenience and the register of the Roman colonizers, as well as the moment the Romans arrived to a concrete place-inasmuch as this later one is likely to give some hints on the particular stage in the evolution of the Latin language as such. Both facts, respectively pointing to a diatopic and to a diachronic stance, are in a way to shape the extant differences one may find, say, between the Catalan and the Romanian. Historical and archaeological evidence show, for instance, that northern and central seaside regions in Catalonia were under Roman command long time before some provinces of the Italian peninsula were; this meaning that the Latin influx in the Dacia, one of the latest spots the Romans conquered, began almost four centuries later than it did in other parts of the roman world. Such a fact is in no way a meaningless minuteness, as eventually it will bring along decisive linguistic consequences [7].

Thirdly, from a sociological point of view, the way the autochthonous population submitted to Rome adopted the Latin should be also investigated in so far as the process of acculturation/enculturation, this is, the way the acquisition and the learning of the Latin as incoming language, could have taken very different formats (on the basis of a scholarly scheduled programme, bilinguistically, diglossically, as an imposition and so forth). Finally, it is worth considering too the imprint exerted by the linguistic superstrata on the "Romanzoid form" ensuing the three aforementioned points. Having said this, it is precisely in light of this fourfold historical template that some fundamentals of the Romance Linguistics touching the Sardinian will be attempted hereafter.

\section{Palaeosardinian, Major Traits of a Twofold Substratum}

It is out of the scope of this article to affirm whether the first habitants of Sardinia were coming from some- 
where in the Middle East, taking Sardinia as a midway dwell in their path to the West-a journey that finally would end up in the valleys of the actual Basque country-, or if in the other way round, they actually moved from the Basque country to the island by sailing alongside the coast of the Gulf of Lyon and the Thyrrenian Sea. What really matters hereby is the linguistic trace left by those former colons, and the way this was to affect the Sardinian language. To put it all in a nutshell, the arguments touching the Sardinian linguistic substratum are of two different order. As it can be presumed, the former responds to the straightforward relation that the scholar community, from the very onset, [8] claimed to see between the non Latin forms in the Sardinian and the preRoman languages spoken in the western side of the Pyrenees. The feature of reliability of the hypothesis arguing for the links between the Palaeosardinian and the Proto-Basque is, furthermore, banking in arguments of archaeological and genetic nature [9].

To bound the issue back to the linguistic field, however, the first shared and common trait to bring up is perhaps the aversion to the phoneme [ $f$ ], particularly in the Sardinian region of Barbagia. In the north-Iberian preRoman languages the voice-lessen evolution of the etymological $[f]$ in initial position, and followed by a vowel, up to the complete extinction of its phonetical value $[\varnothing][10]$ is recounted by means of an aspiration that will become entirely voiceless in the long run. The transition from a labiodental voiceless sound $[f]$ —again, absent in Basque - to a completely voiceless sound $[\varnothing]$ is generally explained in virtue of an intermediate bilabial voiceless sound [p] [11]. In reliance with this, there must be noted that the Sardinian speakers of the small town of Ovodda, in the region of Nuoro, still maintain the $[f]$ in initial position as an aspirated. The second trait resembling the Paleosardinian to the earliest forms of north-Iberian language is the addition of a prosthetic vowel in the words beginning with $-r$ [12]. By the same token, as we shall see, also seemingly owing to a Bascoid substratum [13] is the "reluctance" of the Logudorese dialect to the palatalization [ $\mathrm{t}]$ ], or put in other words, the maintenance of the velar value of $[\mathrm{k}]$ in initial position, as this is clearly at odds with the general trend in the majority of the Neo-Latin languages.

By far less noticeable, though unfair if left either aside or behind, is nonetheless the linguistic substratum attributed to the Phoenicians, the Mediterranean people from north Africa who, in alliance with the Etruscans, won the hegemony of Sardinia to the Greeks in the battle of Alalia (ca. 537 BC) [14]. After that, the Phoenicians_-or Carthaginians—settled namely in the central and southern areas of Sardinia for a period of 400 years; until the Roman conquest. As the autochthonous Sardinian people they encountered, the Carthaginians neither spoke an Indo-European language. This not only is felt in the toponymy of several places in the south of the island [15], but also helping in the rise of almost two of the most distinctive phonetical traits in the southern and the middle forms of Sardinian, specially, again, in the area of Barbagia: the glottid stroke in place of $-k,-l$, and $-n$ (no doubt a condition present in the languages of the Semitic family); and on the other hand, the cacuminal phonemes corresponding to the emphatic consonants of the Berber dialects [16]. A further element to consider within this last second trait is the cumiminal articulation of certain consonantic groups in final position [17].

\section{The Sardinian in the Hinge of the Romances, Some Historical and Linguistic Features of Relevance}

Sardinia was among the first territories the Romans wrested from their rival, Carthage (238 BC) [18]. The majority of handbooks dealing with our concern tend to highlight the conservative of the Sardinian. The Logudorese and the diverse variants spoken in Barbagia [19] reflect the speech of the areas where the Latin influence was minor. Apart from the phonetical consequences the pre or non Indo-European substrata brought about, the aloofness of the insular condition featured the Sardinian lexical in that conservative way too. By way of example, it must be mentioned that a considerable number of words in Logudorese were built on the nominative case in Latin [20], when the rule says that the lexikon informing the Romance languages is normally on the basis of the accusative. For preserving Latin words that are not present in any other Romance language, the Sardinian is indeed a treasure from the point of view of the vocabulary [21].

The Roman conquest of the island neither was easy nor bloodless. Beside Sicily and Mauritania, the southern part of Sardinia was rich in crop and cereal, this turning it into a focus of grain deliverance of the utmost value, as the constant campaigns of belligerence to which Rome was committed required a huge demand of flour to feed the troops unceasingly moving. In addition to this, in the eyes of the Romans the strategical location of Sardinia in the Mare Nostrum was a privileged one. Nobody knows exactly how hard the dominion of the whole island was, but it is sure that the aboriginal population, the Ilienses, put fiery resistance fighting off the Roman occupying army. As it was in other provinces of the Roman world, perhaps the best known being the dramatic 
row of violent disorders along through the first century AD in Palestine, the historical reports speak of very combative groups hiding in the wilderness of the spiked ranges of the actual provinces of Nuoro and Ogliastra; hence the Romans named those spots Montes insani [22]. The force called up and sent off to put order on the island was the Cohors Aquitanorum [23], whose major effectives came from northern Africa and Aquitany; these latter ones thereby original from a non Celtic speaking region of the SW France [24]. All this, in sum, is pointing to the fact that certain social layers of the aboriginal population of Sardinia might have been acquainted with the language of the invaders, but this situation was at all the current for the whole of the Sardinian people.

The cross-cultural ensuing battles, historical enterprises, and politic affairs is of course crucial, but in no way can substitute the scientific task in its tentative to describe and explain the phenomena. In abiding the principles of the systematic opposition [25], the Linguistics is either able to regain the etymology of a given word, in the way the experts in Indo-European operate, or to predict the natural outcome of a particular stem, in the manner the Romanists do with the Latin. There is so to speak a tailor-made linguistic rule for this latter up-down process, in the sense that is proved satisfactory enough in terms of explanation when applied to Sardinian, all the more when the results come contrasted with regard to the Italian language; we are referring to the Law of the Quantitative Collapse (LQC hereafter). When the vocalic quantity is considered, it turns out that the vocalism of the classical Latin is featured with 10 different vowels [26]; this owing to the import that the length of a particular vocalic sound played, at a productive level, in "fusional" languages like is the case of the Latin. The variation in the length of a vowel supplied the intended meaning in those random cases where a substantive could stand for several cases in the inflection (Gr. $\pi \tau \tilde{\omega} \sigma ı)$ ) [27].

As far as the evolution into Logudorese Sardinian is concerned [28], the vocalism of the Latin follows a symmetric pattern, since according to their respective quantity every couple of vowels is leading to a single result in terms of pitch [29]. This is why one could claim that an [i] in Logudorese is at the end of the day the in-

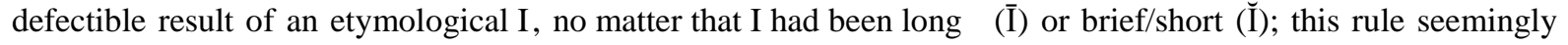
applicable to the rest of the extant vocalic pairs [30]. By contrast, when insight is shed upon the Italian language or the Campidanese dialect, the phonetic array the LQC gives rise is completely other, since the vocalic output is, at this stage, already increased in number. Instead of five vocalic sounds, on the way to Italian and to Campidanese the vocalism of the Latin generated two new more phonemes; [ $\varepsilon$ ] and [ $\supset$ ] [31]. This seven-vowel system without quantity is to be found in the majority of Romance languages.

What has been recounted hitherto, thus, should serve to see that the effects of the agency of the LQC on the Latin are as manifold as Romance languages, in so far as the LQC is at last the responsible of the Romance languages we know today. Yet, by itself and all alone, the LQC could barely suffice to explain the appearance of the Sardinian phonetics to-day. As a matter of fact, with the LQC there is another phonetic rule definitely intervening in the aspect of the Campidanese Sardinian nowadays: the metaphony, metaphonesis or vocalic mutation [32]. The metaphonesis is another basilar linguistic law, but in contrast to the LQC, the metaphonesis is a synchronic one [33]. There is no need to resort to any earlier stage of the Campidanese to predict how a non stressed vowel is to affect the preceding stressed one in a very word. Therefore, because of being the most liable to change, the principles ruling over the metaphony constrain the medial vowels, $\breve{\mathrm{E}}$ and $\breve{\mathrm{O}}$, to come out as [ $\varepsilon$ ] and [ว] whenever the next two conditions are given at once:

1) The etymological $\breve{E}$ and $\breve{O}$ must be allocated in a stressed/tonic syllable (').

2) The different levels of height of the final non-stressed vowels (or stressed off vowels) in the very word will determine whether the precedent $\breve{\mathrm{E}}$ or $\breve{\mathrm{O}}$ in tonic position will finally be lengthened or not [34].

In light of these two metaphonetic rules, therefore, one might finally find out the reason for some of the actual phonetic traits in the southern dialectal form of Sardinian, as well as in the Italian [35].

\section{Superstrata, the Linguistic Heritage of the Later Settlers}

In the Modern era, two were namely the final touches spinning the last steps in the evolution of the Sardinian to its actual appearance. Inasmuch as entirely informing the phonetic physiognomy of the Campidanese, the first one to which the attention should be drifted is the itacism, a lineament straightforwardly ligated with the hegemony of the Greek as the vehicular language of the culture in the Middle Ages and the Byzantine period. By "itacism" it is basically menthe collision a vowel whatsoever into an i [i]. As to Campidanese dialect, the itacism is reflected in the fact that e and o in final position turn respectively into $\mathrm{i}$ or $\mathrm{u}$. It is a well-known and widely attested trait in modern Greek as well, in virtue of which a long e (Gr. $\eta$ ) is actually pronounced as an I [36]. As 
regards the second of the modern influences the Sardinian received, everybody will admit that the most salient one was the lexical that the Catalan [37], afterwards the Spanish domination of Sardinia exerted on the Sardinian superstratum. Both lasting approximately for a period of five hundred years (1323-1840) [38], terms of very common use were simply borrowed from any of the two languages. Some of this new vocabulary remained just invariable [39], whereas other loanwords gave rise to apparent neologisms on the basis of phonetic distort.

In another order of things, this is, despite not owing to a process of lexical loan, one of the most interesting facets in virtue of which the Catalan — in its balearic dialectal variant — could be liken to the Sardinian is nevertheless a striking coincidence, this consisting in the fact that to function as the definite article the same grammatical solution was adopted in insular context. A closer insight upon the issue reveals that balearic Catalan and Sardinian made use of the anaphoric IPSE-derived forms of the Latin—ipsu(m), ipsa(m), ipsos, ipsas—in lieu of the cognate forms of illu(m) to be found either in the Catalan spoken in the mainland, in French or in Italian [40].

\section{The Sardinian Today, a Critical Assessment}

I do hope the reader will have found so far outlined some of the main characteristics I was willing to report in regard to the Sardinian. It would be somewhat senseless, therefore, to keep on abounding and lingering for more time on that. The reader specially interested in Sardinian will find further information, and in more detail, in the bibliography below. It looks to be much more telling instead to conclude this article by saying some about the actual state of the Sardinian; which is the feeling one may get concerning this issue, what kind of expectative for the future it holds, how healthy it is and questions alike. I regret to say that I am not in a position to give figures, ciphers, or numbers to bank the last leg of this article; the works devoted to this concern are in progress, but to be honest, such an approach is clearly falling out of my field of expertise. I will just bound myself to recount some generalities as far as I think these are not far from truth. The assessment of the portrait will be, of course, up to the reader. I am neither akin to any particular ideology nor I am speaking on behalf of someone else. To dispel eventual and licit doubts, and to convince the reader that my claim is not a deviated one, I should like to draw the attention to a few set of incontestable circumstances which are likely to come upon.

The tendency among insular languages to develop dialectal forms and localisms may be a stimulating never endless source of study for the philologist, but a hindrance when it comes the time to create a standard language. In the case of the Sardinian, the Campidanese was the dialectal form taken in view of fixing its prescriptive usage. As we have seen, regardless of not being the most representative variant of the conservative uniqueness of the Sardinian, the reason for the choice probably obeyed to pragmatic reasons; as the Campidanese is in a way recollecting the speech of the main city, Cagliari, and the villages of the Hinterland nearby. However, Cagliari is perhaps the worst place to go for anybody with the serious aim of learning about Sardinian. The price the city has paid for its preponderance is the factual lost of the Sardinian in the public sphere and the everyday life; else its reduction to a certain exoticism that merely calls the attention of the casual tourist that, for the common, knows nothing about the situation. Business, transactions, and cultural events the like are mostly performed in Italian. Signs in the streets, in commerces and in public buildings are either only in Italian. Since being at least an autonomous region of Italy, Sardinia must have therefore the Italian as official language, and there would be nothing bad in that at first sight if not for the clear unbalanced condition that Sardinian has to stand.

Beside other linguistic realities also present on the island, the juridical status of the Sardinian-this is, in the eyes of the central government in the continent-the Sardinian is deemed to be a minority language. It is, certainly, far better than no kind of recognition, indeed, a much more comfortable position than any other the Sardinian probably ever had in the past; yet it seems that, at best, it is but an euphemistic or politically correct way of institutionalized diglossia. In Cagliari, the Sardinian is not used to any extent at the institutional or the administrative level, nor in court, nor in the city councils, nor in the media. The young educated generations brought up in Cagliari, those who actually ought and are able to carry out an educative task whatsoever, have no qualms about admitting that the Sardinian they speak-if they do-is a really limping one, since they only use it when addressing to their grandparents who, for having been born and raised in the countryside are illiterate. Many of these young ones affirm, in addition, that despite having both parents by Sardinian natives they have been always talked and told in Italian. As a result, they can follow a conversation in Sardinian for a short time and for factic functions, but they feel uneasy, unsure, and no fluent enough so as to entertain in a normal conversation in Sardinian. All as the situation worsens and become odd and odder when they are asked with sharper questions: 
the majority of them do not have a clue of the principles ruling the grammar and the orthography of the Sardinian, nor consume cultural products in Sardinian, say, books, movies, reviews, journals, TV programmes. It is perfectly forgivable and it is not their fault, it is rather all about the offer, which is none. With the exception of the mild success of two or three musical formations rapping in Sardinian among few and scattered groups of young people, as far as it goes the panorama is quite dramatic. Inasmuch as responding to the manifold of the cultural demand such an initiative is promising, the problem is that there is almost nothing else besides, so that the punctual endeavors the like-apart from the scarcer audience that may have-are unlikely to find fund neither the proper recognition in a higher or wider cultural field; herewith sentenced to fall soon into oblivion. In Cagliari and its urban area the Sardinian, if present, can be reduced to a handful of regional idioms and the characteristic of its melody, by the rest to the domestic domain, and namely, among the elders. The generational gap is, thereby, outstanding and very seldom bridged. The reasons why are several and of different order, but what the Sardinian evokes first among the young generations is rudeness and poor education, something that has to do with old passed things, with shepherds and a wide array of really nice ancestral traditions, but from the window behind. The Sardinian narrows the chances for the future and is shrewd by an halo of failure; by the time being it is not challenging enough so as to awaken the minimal spark in those who are the single ones enabled to keep the Sardinian alive because they, in fact, ignore it.

\section{Conclusion}

One may think that I am portraying the issue with an exceeding alarm, as things seem to take another way when Cagliari is out, and to some extent that is true. The streets in the villages are often written in Sardinian. It becomes also more normal to listen to the people chatting in Sardinian. Once in the countryside one gets the impression that definitely is in the middle of a very particular linguistic scenery. This, no doubt, confers a more vivid allure to the whole thing, but only in appearance. It is always difficult to state such things, and I would like to be utterly wrong; but in the actual state of things, this is to wit, in the absence of a real serious political commitment to promote the learning of the Sardinian from the early stages of the education up to the university, as well as to make it present in the most important aspects of the everyday life, I fear lest it could well be that the Sardinian would end up disappearing in the next two or three generations. By this I am not sentencing the Sardinian nor intending a literal meaning, rather foretelling its death from a linguistic point of view: when a language meets the expectations of no future the young generations above are afraid.

\section{References}

[1] $\mathrm{A}=\mathrm{B}, \mathrm{B}=\mathrm{C}, \mathrm{A}=\mathrm{C}$ first expounded in Aristotle’s Metaphysics A I, 981a 5-9.

[2] $\mathrm{A} \rightarrow \mathrm{B}, \neg \mathrm{A}=\neg \mathrm{B}$.

[3] As opposite to the Classical, or Fixed Latin, by vulgar Latin it is here meant the evolving spoken language of the first centuries AD among the populations of the Roman Empire. Cf. Coseriu (1987), p. 56; Alkire-Rosen (2010), p. 5.

[4] http://en.wikipedia.org/wiki/Second language acquisition. From the midst 60's of the last century onwards the American linguist S. Krashen devoted his effort to reckon the processes and the strategies the speakers of a language L1 put in practice to acquire, make sense, and-in the best of cases-become fully competent in a target language. This altogether gave pace to the theory of the Second Language Acquisition.

[5] E.g. *mi ho messo la tuta; *Giovanna si ha tolto gli occhiali (En.*I was put my sport suit on; *Giovanna was taken her glasses off) Cf. Renzi (1992), p. 195.

[6] E.g. *stasera ho visto a Giovanna (as if in English one would say *I have seen the Giovanna this eve). The reason underpinning the mistake probably owes to the fact that the normal construction in Sardinian is built with preposition, while in Italian is not. With $1.5 \mathrm{~m}$. of speakers, by way of guidance, the Sardinian is the group of kindred dialects to which the Latin gave rise in Sardinia, being exceptions the city of the Alghero, where Catalan is spoken, and the southwestern emplacements of Carloforte and Calasetta, in the islands of S. Petro and S. Antioco, where an archaic form of the dialect spoken in Genoa is preserved, the so-called tabarchino. Cf. Tagliavini (1982), p. 388; Renzi (1992), p. 70.

[7] Dacia was annexed to the Roman Empire under Trajan (98-117 AD).

[8] M. L. Wagner put the cornerstones of all the enterprise to come, but perhaps it was J. Hubschmid who most eagerly defended this position.

[9] This point is expounded in detail in Blasco-Francalacci-Nocentini (2013), pp. 7-34. 
[10] This is $(f+\mathrm{v}>\mathrm{h}[\varnothing]+\mathrm{v})$.

[11] Such a transitional phoneme is attested for instance in modern Japanese; ऊ [hu]. Its correspondent aspirated and bilabial cognate forms are, of course, contemplated in Japanese, but for the non-native Japanese speaker it is certainly difficult to tell apart if the sound represented by 3 actually corresponds to [f], to [p] or to a lenited glottid stroke [?u].

[12] Tagliavini (1982), p. 125.

[13] E.g. Lat. quinque ['kwinkwe] (En. five) > Log. Kimbe ['kimbe], while in Camp. Cincu ['t tinku]). Cf. Alkire-Rosen (2010), p. 56; Tagliavini (1982), p. 390. The word for "Friday" is not only another sample of this very fact-Log. kenapura whereas in Camp. cenabara (En. pure supper)—but also of a superstratum with evident Semitic roots.

[14] As a result of the victory, Sardinia came to be part of the Carthaginian empire, while Corsica and the Gallura (the northeastern part of Sardinia) were handed down to the Etruscans. To a good extent this was to cause the actual differences between the Sardinian either the Corse and the Gallurean dialect.

[15] Evidence of this influence is the name of the emplacement called Macomer whose purported stem is said to be the Phoenician maqom (En. city, emporium, market). Cf. Wagner (1950), p. 144.

[16] Tagliavini (1982), p. 125.

[17] This is ll [l:] into [dq:] (l: > dq:). Regardless of the usage of [qd:] is namely bound to initial and medial position, it is taken here notwithstanding in virtue of its cacuminal nature. E.g. Lat. CABALLUS> Sar. caddu ['kwadd:u]. As a title of anecdote, "caballus" is neither the classical nor the vulgar Latin word for "horse" but EQUUS. Related to the Gr. $i \pi \pi \mathrm{o}$, , this would fit in the general and accepted rotation that there is to be found between [p] and [k] in Indo-European. In the opinion of the romanist J. Coromines "caballus" would rather be a loanword from a Gallic language that Latin incorporated by the second century BC. Cf. Coromines (1992), p. 647.

[18] Tagliavini (1982), pp. 122.

[19] Renzi (1992), pp. 170-171; Tagliavini (1982), p. 392.

[20] E.g. Log. sorra results from the Lat. soror in the nominative not in the accusative sororem (En. sister). Renzi (1992), p. 140.

[21] Lat. iuba > Camp. yuba (En. mane); Lat. coniugare > Log. koyuare (En. to get married); Lat. porcus aper > Log. porkavru (En. wild boar). As regards this last one, it is also attested the form porcu arestu. Cf. Tagliavini (1982), p. 392. What really matters, nonetheless, is the fact that in the majority of Romance languages (Cat. senglar, Fr. sanglier, It. cinghiale) the wild boar is named by the purported Latin stem singŭlāre, i.e. single, alone.

[22] Cf. Strabo Geography XVI, 1, 17-18. Both, (Il)-ienses and (Ogli)-astra, are recalling the purported connection of the Proto-Basque with Palaeosardinian.

[23] The purported date for the rising of the Cohors Aquitanorum can be traced back to the first century BC, in particular, by the time of Augustus.

[24] This fact is deemed to have strengthened both of the layers in the non Indo-European linguistic substratum of the Sardinian above described, the Bascoid and the Phoenician.

[25] Coseriu (1987), pp. 53-54.

[26] These being $\overline{\mathrm{I}}, \breve{\mathrm{I}}, \overline{\mathrm{E}}, \breve{\mathrm{E}}, \overline{\mathrm{A}}, \breve{\mathrm{A}}, \breve{\mathrm{O}}, \overline{\mathrm{O}}, \breve{U}, \bar{U}$ and resulting from the two basic quantities (long and short) multiplied by the five basic vocalic timbres/pitches (a, e, i, o, and u).Yet, properly speaking, since [a] lost its quantity in a very early stage of the process the different vocalic phonemes in the system could be reduced to 9. Cf. Alkire-Rosen (2010), p. 9.

[27] As it goes, for instance, in modern Slovak and other languages of inflecting type. From a typological point of view the main difference one might find between the Latin and the Romance languages is that the former is regarded as a synthetic language while the Neo-Latin ones are said to be analytic. Cf. Renzi (1992), p. 306; Coseriu (1987), p. 61. At any rate, in Latin and in ancient Greek the substantives neutral-characterized by the oblique case due to the absence of barytonesis in the vocative singular-present the same form for almost three different syntactic functions (casus rectus). Hence the way to say in Latin make a mistake or to be wrong was aequivocare, i.e. to call two things by the same word. The misunderstandings provoked by this phenomenon did not pass unnoticed and it was very soon described. In Categories 1a 1-15, for instance, Aristotle made reference to this by the tenet "paronymy".

[28] It is credited that by the sixth century AD the language(s) spoken in Sardinia did no longer reflect the written Latin in the texts, up to the point that Latin became unintelligible to Sardinian speakers (and vice versa). The gradual and irreversible drift of the newborn Sardinian away from the Latin ended up constituting the Sardinian into a completely different linguistic entity. As a similar process is deemed to have occurred with the majority of the Neo-Latin languages there is no room for a doubt about the real novelty the Romance languages entrained with regard to Latin. Pulgram's view is somewhat contrary to this, since he claims to be a continuity between the Latin spoken and the Romances, whereby the blank to which we refer is in Pulgram's opinion of diasystemic or diamessic nature, this is, between the way(s) the Latin was spoken and the way it was written, i.e. within a very and single language. Cf. Pulgram (1987), pp. 189-191. 
[29] That is to say: $\overline{\mathrm{I}}, \breve{\mathrm{I}}>[\mathrm{i}] ; \overline{\mathrm{E}}, \breve{\mathrm{E}}>[\mathrm{e}] ; \overline{\mathrm{A}}, \breve{\mathrm{A}}>[\mathrm{a}] ; \overline{\mathrm{O}}, \mathrm{O}>[\mathrm{o}] ; \overline{\mathrm{U}}, \breve{\mathrm{U}}>[\mathrm{u}]$.

[30] Lat. FīLIUM $>$ Sar. fillu ['fil:u] as well as Lat. PǏRA> Sar. pira ['pira].

[31] In virtue of the LQC, $[\varepsilon]$ and [o] in Italian are the respective outcome of the $\breve{E}$ and the Ŏ in Latin. It is important to note that these two phonemes would experience a process towards diphthong in open (light or free) syllable, e. gr. Lat. DĔCEM > It. dieci ['dje(t)fi]; Lat. OVUM > It. uovo ['uoßo]. The typical paragogic vocalism that Sardinian speakers deploy (e.gr. tui pigas ['tui' $\beta i$ izaza]) is strongly contrasting with the fall of the final etymological -s in the majority of dialectal forms developed in the Italic peninsula and in Rumania, this being in turn a definite difference between Western and Eastern romances. Cf. Renzi (1992), p. 197. On the other hand, nonetheless, the paragogic vocalism is said to be of epenthetic nature, contributing in a way to the apparent predilection of Sardinian for free- or light—syllabic unities, this is, not blocked by a consonant. Cf. Blasco (2009), p. 92; Herman (1987), p. 97; Alkire-Rosen (2010), p. 12.

[32] By metaphony it is intended the assimilatory rising of vowels in anticipation of a following, higher, phoneme, typically a high vowel or a glide. Cf. Penny (2002), p. 47.

[33] Renzi (1992), pp. 58-59.

[34] While i and $\mathrm{u}$ are considered high vowels, a, e, and o are regarded as middle or low ones.

[35] In accordance with the metaphony we get then Camp. bene ['bene] < Lat. BĚNE (En. well); Camp. coda ['kəða] < Lat. CODAM (En. tail).

[36] Started to be written in the second and the third century AD with the aim of representing the popular speech in Egypt, the Coptic clearly falls out of the category of a Romance, belonging in fact to the branch of the Hamito-Semitic languages. If it is brought up here it is in order to enhance the influence of the Greek superstratum. By judging the often presence of itacism in some dialectal forms of the Coptic, specially the Lycopolitan, one might presume that itacism was already a linguistic dominant during the Roman Imperial period.

[37] Cf. Ledgeway (2012), pp. 100-101.

[38] Regardless of the dissent as regards the dates given, the point is that many Sardinian authors composed and wrote in Catalan during the Catalan dominion, as well as the Spanish was the official language of the laws and the instruction until the 1720

[39] Cat. Baldufa > Camp. bardunfola (Cagliari), budrunfa (San Sperate); Cat. rata-pinyada/rat-penat > Camp. ratapignata (only in Cagliari)—while in the small village of Seulo this winged mammal is known by fericonca elsewhere in Sardinia is called zurrundeddu) —; Cat. cadira > Camp. cadira.

[40] Tagliavini (1982), p. 391. The fundamentals of Indo-European linguistics point to the fact that the apparition of the article as semantic item is one of the latest turns that some-not all-European languages took. As to Sardinian concerns, it suffices to say that neither there are forms of definite article nor traces of indefinite one prior to the Middle Ages. Renzi (1992), pp. 143-144.

\section{List of Abbreviations and Signs}

*: non grammatical sentence;

En.: English;

Fr.: French;

[...]: phonetic transcription;

Gr.: Greek;

Camp.: Campidanese, southern dialect of Sardinian;

It.: Italian;

Cat.: Catalan;

Lat.: Latin;

Cf.: confer;

Log.: Logudorese, central dialect of Sardinian;

E.g.: exemplum gratia;

Sp.: Spanish. 